\title{
eHealth policies that underpin global health care digitisation: A review
}

Dr. K. K. Pradeep Sylva BDS (Peradeniya), MSc (Colombo)

Dental Surgeon (Health Informatics), Ministry of Health

Colombo 10, Sri Lanka

E-Mail address: pradeepsylva@gmail.com

Dr. H. M. N. Buddhika Abeysinghe MBBS (Kelaniya), MSc (Colombo)

Medical Officer, Ministry of Health

Colombo 10, Sri Lanka

E-Mail address: buddhika.abeysinghe@gmail.com

Dr. Clive C. James MD(St.Petersburg), MSc (Colombo)

Medical Officer (Health Informatics), Ministry of Health

Colombo 10, Sri Lanka

E-Mail address: clive.jms@gmail.com

Dr. A. M. Anuradha Jayatilake MBBS (Colombo), MSc (Colombo)

Medical Officer, Base Hospital

Homagama, Sri Lanka

E-Mail address: jayatilake76@yahoo.com

Dr. Sonali A. Lunuwila MBBS (Karapitiya), MSc (Colombo)

Medical Officer (Health Informatics), Ministry of Health

Colombo 10, Sri Lanka

E-Mail address: sonaliapsara@gmail.com

Dr. H. T. Deepaka Sanath MBBS (Colombo), MSc (Colombo)

Medical Officer (Health Informatics), Medical Research Institute

Colombo 10, Sri Lanka

E-Mail address: dchanduni1999@yahoo.com

Dr. W. K. D. K. K. Wijayaweera MBBS (Colombo), MSc (Colombo)

Medical Officer (Health Informatics), Ministry of Health

Colombo 10, Sri Lanka

E-Mail address: kusalwijayaweera@yahoo.com

Dr. W. M. Arjuna Wijekoon MBBS (Kelaniya), MSc (Colombo)

Assistant Director (Health Information), Provincial Department of Health Services

North Western Province, Sri Lanka

E-Mail address: aawijekoon@ gmail.com

Sri Lanka Journal of Bio-Medical informatics 2011:2(4):118-129

DOI: http://dx.doi.org/10.4038/sljbmi.v2i4.2447 


\begin{abstract}
Healthcare systems in both the developed and the developing world face many challenges including demand for higher quality and equitable distribution. The healthcare organisations and the governments alike have focused on eHealth as an adjunct to overcome these challenges. In the backdrop of sporadic initiatives running parallel to this thought, the realisation of the need for long term strategy, policy guidelines and standards have been indeed swift. Thus, most pioneers of healthcare digitisation have drafted and implemented such policies to varying degrees, to date. This review was aimed at analysing eHealth strategy and policy related documents currently available and identifying crucial policy issues which require emphasis. Academic articles on eHealth policy and policy related documents of USA, Australia, Canada, Ethiopia, Scotland Europe, WHO and Commonwealth were included in this study. These articles were reviewed based on a set of predetermined eHealth policy related issues comprising of; 1 . Vision, Mission, Goals and Objectives 2. Operational Framework 3. Legislation 4. ICT Management 5. eHealth Infrastructure 6. Capacity Building in ICT 7. Financial Resource Assessment and 8. Procurement and Contractual Issues. While most policies did not address all the predetermined criteria considered in this review, some deficiencies were due to variations in ICT usage and existing infrastructure of the observed countries. Elements of interoperability through data, software, hardware, web and mHealth standards, data security and privacy, accessibility and reliability formed the backbone of all eHealth policies, though none of the documents under review expressed expected levels of completeness. Thus, further work is needed to scientifically map the ground situations of ICT usage and infrastructure to policy issues addressed and to analyse the results to justify the emphasis given to such issues. Though the task of identifying the perfect mantra for eHealth policy seems daunting, it is indeed worthwhile, since an unimaginable array of benefits of healthcare digitisation awaits every nation.
\end{abstract}

Keywords - eHealth; Policy; Strategy; Telemedicine; Guidelines; Review

\title{
Introduction
}

Healthcare systems around the globe embrace eHealth as a solution to the current and emerging healthcare issues. In this context, WHO defines eHealth as the use of information and communication technologies (ICT) for health ${ }^{(1)}$. In practical terms, eHealth is the use in the health sector, of digital data (transmitted, stored and retrieved electronically) in support of healthcare, both at the local site and at a distance ${ }^{(2)}$. As the need for eHealth becomes more evident to governments, the effective development of eHealth and its integration into mainstream health care is deemed to be best achieved through the creation of an eHealth strategy, with the support of appropriate policies ${ }^{(3)}$.

Healthcare digitisation promises long-term benefits. An advanced healthcare environment integrating eHealth streamlines the secure delivery of healthcare information, stripping away repetitious and inefficient processes. This paves the way for a stepwise improvement in health system performance in effectiveness, efficiency, safety of care, responsiveness, continuity of care, accessibility and sustainability ${ }^{(4)}$. Moreover, these outcomes would facilitate countries to reach and attain health related Millennium Development Goals of reducing child mortality rate, improving maternal health and combating HIV/AIDS, malaria, and other diseases ${ }^{(5)}$ and thereby reap the benefits of healthier citizenry.

\section{Rationale}

Although research around practical integration of e-health policy is increasing, much work is needed in understanding the breadth and depth of the related policy issues. Greater comprehension and awareness of these issues would better equip the healthcare administrators to address them ${ }^{(6)}$, thus increasing the viability of implementation and sustainability of such 
systems. The objectives of this study are aimed at identifying evidence on eHealth policies and strategies adapted (2000-September 2010), their enforcement and their reviews, appraise and summarise such according to a set of predetermined criteria. It is also intended to be analytical and provide an overview of the evidence of reasonable change on the efficacy, effectiveness, and economic effect of eHealth applications based on these policies, as a guide to decision makers in healthcare.

\section{Methodology}

Computerised literature searches were performed using indexing services of PubMed (2000September 2010), IEEE Xplore (2000-September 2010) and EMBASE (2000-September 2010). Search strategy was based on the key words eHealth, eHealth policy, eHealth strategy, review + eHealth policy, review + eHealth strategy, Healthcare IT, and Tele-health. Further, eHealth was replaced with e-Health in all relevant instances. Inclusion criteria were as follows: articles which sufficiently addressed one or more of the predetermined analytical criteria in a scientifically valid manner. The exclusion criteria required the rejection of articles which evaluated hypothetical scenarios. Articles that were duplications of the same authors' other published

studies; the most representative of the studies was included for further consideration. Google scholar search engine was used to obtain eHealth policy related documents of USA (Health IT Strategic Framework and The ONC-Coordinated Federal Health IT Strategic Plan; 2008-2012), Australia (National E-Health Transition Authority-NEHTA), Canada (Ontario's eHealth Strategy; 2009-2012), Ethiopia (Ethiopian ICT Policy), NHS-Scotland (eHealth Strategy 20082011) and Europe (RIDE - A Roadmap for Interoperability of eHealth Systems in Support of COM 356) representing three continents and to obtain eHealth policy related documents of WHO and Commonwealth (2000-September 2010).

\section{Results}

\section{Analytical framework}

A comprehensive analysis was carried out based on eight predetermined criteria extracted by careful scrutiny of eHealth policy related documents of: Basic Operational Framework on eHealth for Health Care Delivery (BOF-eHCD) of $\mathrm{WHO}^{(7)}$, eGoverment Policy of Sri Lanka ${ }^{(8)}$ and Commonwealth Secretariat - eHealth initiative ${ }^{(9)}$. These criteria are; 1.Vision, Mission, Goals and Objectives 2.Operational Framework 3.Legislation 4.ICT Management 5.eHealth Infrastructure 6.Capacity Building in ICT 7.Financial Resource Assessment 8.Procurement and Contractual Issues.

\section{Vision, Mission, Goals and Objectives}

All eHealth policy and strategic documents selected in this review (100\%) had clear visions. The main focus of all the visions was improvement of or support of healthcare provision by harnessing Information and Communication Technology (ICT). The RIDE document focused on a "Semantically Interoperable eHealth Infrastructure ${ }^{(10)}$ " for cross border healthcare information 
exchange and interoperability. Though mission statements per say were absent from a majority of documents clear goals and/or objectives were indicated in almost all of them. The USA and NHS-Scotland documents addressed the objectives of improving health outcomes, quality, patient safety, patient engagement, care coordination, and efficiency of the health care system. Further, making available the right information in the right place at the right time, enabling more efficient use of health-care resources, safeguarding confidentiality by handling patient information by incorporating effective privacy and security solutions, development and support of appropriate policies and technical specifications were also clearly described. The USA document sets a goal of transforming the current health care delivery system into a high performance learning system by leveraging health information and technology. The NHSScotland has identified the objective of contributing to 'health literacy' which ensures that all citizens to have the necessary skills, knowledge and confidence to manage their own health ${ }^{(11,12)}$.

\section{Operational framework}

Documents of NEHTA, USA and NHS-Scotland had a specific timeframe of action depending on the current status of digitisation and the expected levels in the future. The broad categories identified in NETHA were; connect and communicate (years one to three), collaborate (years four - six) and consolidate (years seven - 10) ${ }^{(4)}$. NHS -Scotland expressed a shorter timeframe with a component for further planning (end of spring 2009). Its other broad constituents were aimed at exploiting and improving what exists (2008 - 2011), making significant procurements or developments (end of 2011) and providing support for delivering the strategy (end 2008) ${ }^{(12)}$. Ontario's eHealth Strategy has a time frame of 2009 to 2012. WHO and Commonwealth documents have not mentioned a specific timeframe since they are more generalised in nature as opposed to country specificity of other documents reviewed.

In general all policies and strategies were directed at achieving better and long standing public and private sector involvement in eHealth, when defining their scope. The USA strategy specifies this by expressing that "The Plan is designed to build upon, leverage, and coordinate the existing and critical roles that many federal, state, local, tribal, and private stakeholders already play in advancing these goals. Many of the strategies proposed in this Plan are designed to harmonise activities in the public and private sectors, to ensure that federal resources allocated

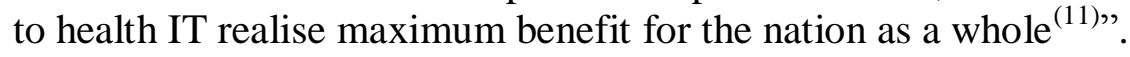

\section{Legislation}

The USA policy document specifies a comprehensive list of enabling acts relevant to healthcare $\mathrm{IT}^{(13)}$. It refers to the American Recovery and Reinvestment Act of 2009 (ARRA), HITECH Act and Health Insurance Portability and Accountability Act (HIPAA). NEHTA and the NHSScotland have little reference to existing legislation but nevertheless identify their importance. eHealth Ontario has a Privacy and Data Protection Policy which specifically states that it is subjected to and must comply with Statutes and Regulations and refers to the Freedom of Information and Protection of Privacy Act (FIPPA), the Personal Health Information Protection Act, 2004 (PHIPA) and the Ontario Regulation 43/02(O.Reg.). 
The intellectual rights are ill defined in most documents. In the NHS-Scotland there are no health specific acts but supportive acts are available in Scotland for data protection, freedom of information and NHS Scotland confidentiality code of practice ${ }^{(14)}$.

Much emphasis is given in almost all documents for data protection, security \& privacy related to eHealth. The USA strategy states that "Privacy and security solutions should be consistent with the Nationwide Privacy and Security Framework for Electronic Exchange of Individually Identifiable Health Information." It also specifies a set of principles which deals with individual access, correction, openness and transparency, individual choice, collection, use and disclosure limitation, data quality and integrity and safeguard accountability ${ }^{(11)}$. The RIDE has addressed in detail issues regarding user authentication, access rights based on 'need-to-know' principle, document authenticity, peer authentication, cryptographic timestamps, audit trail, emergency access, cross jurisdictions, managed consent and identity registries ${ }^{(10)}$. eHealth Ontario Privacy and Data Protection Policy further emphasises on developing a comprehensive provincial strategy for managing consent and implementing and enforcing consent directives for all eHealth solutions in compliance with the PHIPA ${ }^{(15)}$.

\section{ICT Management}

\section{Standards}

The importance of establishing and adherence to standards, guidelines and implementation specifications is strongly recommended in all policies. The importance of data standards which recommends common terminologies and data representation and networking standards which ensure standard messaging, secure messaging and message acknowledgement are highlighted in the NEHTA document. NHS-Scotland emphasises on common data standards which leads to ease of access, and integration between systems. Although, it further recognises the importance of interoperability of core components, technical details were not included. The RIDE document however sufficiently addresses these in detail.

There is little mention about the hardware standards, web standards and mHealth in any of the documents under review.

The use of modern wireless telecommunication means like GSM and GPRS as well as satellite communications, allow the operation of wireless telemedicine systems freeing the medical personnel and patients bounded to a fixed location. The importance of forthcoming UTMS mobile telephony standards in this aspect is clearly understood ${ }^{(16)}$.

Further, a "glocal" e-health policy is defined as one which engages the wisdom and experience of stakeholders at the global and local levels. The importance of a "glocal" eHealth policy as opposed to a global or local policy is expressed after analysing EU, Canada, India and Malaysian policies $^{(17)}$. Ontario's eHealth strategy refers to the Ontario Health Informatics Standards Council which discusses pan - Canadian standards as an important aspect of global information exchange and strongly recommends same. 


\section{IT governance}

Achieving a new information governance consensus focused on better use of information and safe guarding information confidentiality is one of the aims of the NHS - Scotland strategy. The USA document focuses on "collaborative governance" for the development of health IT infrastructure and for the information use for population health. NEHTA recommends the formation of a governing body once the eHealth policy and the roadmap document is complete. These bodies are to look into the relevant areas of the eHealth roadmap.

\section{Information lifecycle management}

Information Life cycle Management (ILM) is a comprehensive approach to managing the flow of an information system's data and associated metadata from creation and initial storage to the time when it becomes obsolete and is deleted ${ }^{(18)}$. The emphasis given to this aspect in all documents is scanty.

\section{5. eHealth Infrastructure}

\section{Data administration}

eHealth Ontario refers to a "data centre" which is managed by it's own staff. Other documents have little reference to this topic.

\section{Network application and Data architecture}

The NEHTA brings individual eHealth application capabilities together and outlines the high level architecture of the national approach to e-health. It has been intended to provide a more technical audience with an overview of the major architectural elements and how they can be used locally. The documents describe in detail aspects of architectural approach, current state architecture, target state architecture, standards, integration architecture and security and access framework.

eHealth Ontario suggests the implementation of all eHealth solutions within a coherent provincial eHealth architecture which is designed to deliver clinical value.

\section{ICT Audit}

While most policies do not addresses this aspect, the NHS-Scotland specifies that eHealth supports patient safety by contributing to create data for ICT audit, improvement and population based studies.

\section{Accessibility and service delivery}


The USA and NHS-Scotland stresses on the importance of accessibility of health information, by individuals, based on legitimate reasons and the interest of the patient. Patients and care givers will have improved access to information about their condition or about a procedure they may have to undergo, encouraging greater involvement in maintaining and improving their own health. The policies also state that information should be provided with a simple and timely means in a readable form and format.

\section{ICT project continuity}

In the 'USA strategic plan' special emphasis is given for periodic updating of the plan and active engagement of other federal agencies in re-evaluating the strategic objectives and strategies, and tracking progress towards such goals and objectives.

\section{Networking and connectivity}

The NEHTA document suggests both a 'web services gateway', to enable secure messaging with a range of systems external to the enterprise and a 'portal', to provide portal style services to providers and consumers who access the enterprise's services externally. Ontario's eHealth strategy describes the Managed Private Network (MPN) deployed, contracted for and funded by eHealth Ontario. Such is provided to all qualified healthcare providers including physician offices, community care access centers and hospitals. It further describes network deployments as slow and difficult, often leading to expectations in the field that are not met.

\section{Web presence}

NHS-Scotland supports the option of a web-based channel for providing access to disadvantaged communities.

\section{Backup measures}

All policy and strategic documents under review have failed to adequately address issues relating to data backup.

\section{Capacity Building in ICT}

Though, a plan for ICT human resource needs assessment is not clearly stated, the NHS-Scotland identifies the importance of staff training. The USA strategy has recognised the need for an increase in and support for, a trained workforce to implement, operate, and effectively use HIT technologies to improve health. It also encourages development and maintenance of national education initiatives to increase consumer awareness and acceptance of knowledge about the benefits of health information exchange. It further wishes to broaden the national dialogue on privacy and security issues and to enhance public transparency regarding the uses of protected health information and individual's rights with regard to protected health information. 
Ontario's eHealth strategy describes the Health Human Resources Expansion Programme. This aims at developing programmes to expand the number of skilled professionals with experience in eHealth-related fields and to explore opportunities to support programmes in Ontario universities and colleges to increase the pool of resources available to contribute to eHealth initiatives. Further, it has identified the development of methods for increasing the complement of skilled staff in IT projects as an important aspect. Apprenticeship and on-the-job training is also highly encouraged.

All policies have failed to mention the need for regulation of certification of ICT qualifications and encouragement of staff to obtain only such qualifications. Further, only the NEHTA strategy has identified the importance of a specific officer for innovation and ICT management in institutions.

\section{Financial Resource Assessment}

NHS-Scotland has recognized the importance of a progressive increase in the eHealth budget for the sustainability of systems. The USA policy refers to the HITECH Act which includes the commitment of significant federal funding to provide incentives for nationwide adoption and use of certified electronic health record (EHR) technology and to support health information exchange. Other documents under review have little or no mention in this regard.

Further, almost all policies and strategies have failed to look into the cost recovery of eHealth systems.

\section{Procurement and contractual issues}

Adequate attention is not given for procurement procedures, procurement budgeting and planning, contractual issues in procurement and role of ICT technical evaluation committees, in most of the reviewed documents. Ontario's eHealth strategy recommends the adaptation of robust, fair and cost effective procurement processes in partnership with Infrastructure Ontario and other organisations. Furthermore, it suggests the application of sound and rigorous contract management practices.

\section{Discussion}

In general, a policy is defined as a principle or a plan of action, or merely a line of argument to justify a course of action, considered to be related to any strategy, programme, roadmap, implementation plan or national action plan. eHealth policy specifically has been defined in stronger language as "a set of statements, directives, regulations, laws, and judicial interpretations that direct and manage the life cycle of eHealth ${ }^{(17)}$," Most often an eHealth policy is "hidden" as part of a larger eGovernment policy or stems from such to a more customised version to suit eHealth per say. Although our results revealed that many countries still lack a proper policy or strategy for eHealth, the need for such in national eHealth initiatives is well understood. This is proven by the amount of attention given to policy and strategy by countries where healthcare digitisation is practically being experienced. Further, the "living" nature of 
such a document is also undisputed. What baffles many are the essential constituents which make up a rational and effective policy, to which this discussion tries to focus all its deliberations.

eHealth is inevitably intertwined with health. For eHealth to be considered a success, its integration with the healthcare delivery system should yield both tangible and intangible improvements in the health status of the populations in question. Further, they should be sustainable and preferably continuously improved, on the long run. The identification of clear visions, missions, goals and objectives in all the policies and strategies and their reference to relevant national health goals strongly supports this relationship. These optimistic statements have specified what is expected of eHealth. The policy issues discussed and the timeframes allocated in these documents highlights what aspects should be strengthened for viability and sustainability, depending on the present satiation of those countries and the expected levels of improvement. The most pressing issues addressed are; interoperability of systems and software, data security and privacy, accessibility of systems. Some of the less noted issues are: reliability of systems, dependability, software maintainability of systems and software, accountability, sustainability and related aspects ${ }^{(20)}$.

Interoperability is defined by IEEE as the ability of two or more systems or components to exchange information and to use the information that has been exchanged ${ }^{(4)}$. In a broader sense this implies the seamless integration and data interchange between intra-institutional systems, between institutions in the same sector and between different sectors. In a much broader sense this concept extends beyond borders to achieve global interoperability ${ }^{(17)}$. Most policies have identified the importance of "local" interoperability though only the RIDE document has identified and encouraged its "global" scope. The importance of establishing and enforcement of standards in data and software were well documented and thus can be considered as imperative. Although, hardware standards, web standards and standards applicable to mHealth have not been discussed satisfactorily, their importance is little questionable when gauged by the attention given to the aforementioned. Establishing hardware and networking standards and guidelines for procurement would ensure incorporation of related technological advancements without any hindrance to interoperability of systems.

Data security and privacy has been extensively discussed in most documents under review, with related laws, recommendations for amendments and formulation of new law as needed. Incorporation of mechanisms to ensure eHealth solutions with stringent data security and privacy is therefore an integral part of an eHealth policy. Concept of "privacy by design" ensures electronic tools and information are designed to enhance, rather than erode, privacy (ie."build in privacy from the start"). Such is a critical enabler of electronic health records because it reduces possible privacy incidents and the resources required to manage them. eHealth Ontario encourages advocating privacy experts and suggest continuous conduct of privacy impact assessments on eHealth solutions ${ }^{(15)}$.

Accessibility of eHealth systems which in turn enables better access of health information is an important aspect of healthcare decision making and care delivery. Policy documents in general have reflected this fact. 
Healthcare delivery is a continuous process with a very high demand for reliability and dependability. Therefore, information systems incorporated has little or no room for related shortcomings. Policies and guidelines should adequately address issues of capacity building for maintenance and establishment of proper network infrastructure. This has not been stressed in most policies under review and can be attributed to the existing quality of the resources available in those countries. Further, building confidence in acceptance of eHealth services is a key to the success of any form of digitisation and organisational change. Ensuring higher standards of patient safety, data protection and privacy has been proposed as means of achieving better acceptance. Therefore, it can be stressed that promotion of awareness, confidence and acceptance by health authorities, professionals, patients and their relatives is of utmost importance ${ }^{(19)}$ and needs support by way of policy and guidelines.

A defined timeframe and scope is viewed as essential for the success for the smooth flow of events in implementing complex eHealth solutions in a volatile environment. Sustainability of these systems has to be critically evaluated. Factors directly affecting this have been identified in some policies as human resource development and finance. The need for support through long term strategy, for adequate needs assessment and training action for both patients and health professionals $^{(19)}$ was expressed in some policy documents. Adequate and long term financial support also has been given much attention in some documents.

This review is focused on the content of different policy documents but little attention was given to the different ground situations which these policies addressed. Though, certain shortfalls of policies can be attributed to such variations, gross inadequacies in certain polices could not be justified. It was also beyond the scope of this review to assess level of implementation of such policies and the effects of same. Further effort is needed to measure the effects of specific policy and strategic guidelines which address specific eHealth issues to properly understand and prioritise them according to their importance.

\section{Conclusion}

While most policies did not address all the predetermined criteria considered in this review, we are well aware that such list is neither the only list nor exhaustive by any means. The reason for the seemingly incompleteness of some policies may be related to the true ground situations which necessitated the limited focus they reflected. Accordingly, indisputable elements of interoperability through data, software, hardware, web and mHealth standards, data security and privacy, accessibility and reliability should form the backbone of all eHealth policies. Elements of maintainability accountability and sustainability should also be included. It can be concluded that there may not be one template for a perfect policy document. Further, work in relation to the review of actual implementation of policies and their results need to be carried out. Based on results of such studies a more accurate list of essentials can be formulated. Healthcare digitisation is inevitable. The future of healthcare delivery will focus on delivery of quality healthcare with an equitable distribution. In this context the value of understanding the essential components of the driving force behind such initiatives is indeed worthwhile.

\section{References}


1. World Health Organization. eHealth [Internet]. Cited 2010 September 09. Available from :http://www.who.int/topics/ehealth/en/.

2. World Health Organization.. eHealth for Health-care Delivery Strategy $2004-2007$ [Internet]. Cited 2010 August 23. Available from: http://www.who.int/eht/en /eHealth_HCD.pdf

3. World Health Organization. eHealth: proposed tools and services [Internet]. Cited 2010 September 06. Available from :http://apps.who.int/gb/ebwha/pdf_files/EB117/B117_15en.pdf.

4. National E-Health Transition Authority. NEHTA Blueprint version 1.0[internet]. 2010 August 13[cited 2010 August 21]. Available from: http://www.nehta.gov.au/about_ us/ nehta-blueprint.

5. World Health Organization. Health - related Millennium Development Goals [Internet].Cited 2010 August 21. Available from: http://apps.who.int/gb/ebwha/pdf_files/EB117 /B117_13-en.pdf

6. British Columbia Alliance on Telehealth Policy and Research. E-Health Policy Study; Telehealth Policy Baseline Study [Internet]. Cited 2010 August 19. Available from: http://www.bcatpr.ca/contact

7. World Health Organization. Basic Operational Framework on eHealth for Health Care Delivery [Internet] Cited 2010 August 19. Available from: http://www.who.int/eht/eHealthHCD_BOF/en/index.html

8. Information and Communication Technology Agency of Sri Lanka (ICTA). Policy and Procedures for ICT Usage in Government [internet] 2009 December 02 [cited 2010 August 21]. Available from:

http://www.icta.lk/attachments/759_ICT_Policies_and_Procedures_for_Government_V_9_ English_Jan_08_2010.pdf

9. Commonwealth Secretariat.e-Health Initiatives [Internet].Cited 2010 September 07. Available from : http://www.thecommonwealth.org/files/228131/FileName/ E-HealthInitiativeslo-res.pdf

10. Middle East Technical University, Software Research and Development Center. A Roadmap for Interoperability of eHealth Systems in Support of COM 356 with Special Emphasis on Semantic Interoperability [Internet]. Cited 2010 August 19. Available from: http://www.srdc.metu.edu.tr/webpage/projects/ride/

11. 11.HIT Policy Committee, USA. Health IT Strategic Framework [Internet]. 2010 May 19[cited 2010 August 21]. Available from: http://healthit.hhs.gov/portal/server.pt/ gateway/PTARGS_0_11673_911844_0_0_18/HIT_Strategic_Framework051010.pdf. 
12. National Health Services-Scotland. eHealth Strategy 2008 - 2011 [Internet] Cited 2010 August 21. Available from : http://www.show.scot.nhs.uk/eHealth\%20Strategy\%20200811\%20final.pdf

13. Minnesota Department of Health. Minnesota Laws Related to e-Health [Internet]. Cited 2010 August 24. Available from: http://www.health.state.mn.us/ehealth/lawsmn.html

14, Scottish Government. Government Records Management: NHS Code of Practice (Scotland) Version 2.0[internet].Cited 2010 August 21.Available from: http://www.scotland.gov.uk/publications/2010/04/20142935/6

15. eHealth Ontario. Ontario's eHealth Strategy 2009 - 2012[Internet]. Cited 2010 August 22. Available from: http://www.ehealthontario.on.ca/pdfs/About /eHealthStrategy.pdf.http://www.ehealthontario.on.ca/pdfs/Privacy/PrivacyDataProtectio nPolicy.pdf

16. S. Voskarides, C.S. Pattichis, R. Istepanian, E. Kyriacou, M.S. Pattichis, C.N. Schizas, Mobile health systems: A brief overview [Internet]. 2002 [cited 2010 Augest 27]. Available from: http://citeseerx.sit.psu.edu/viewdoc/summary?doi=10.1.1.83.9908

17. Maurice Mars, Richard E. Scott. Global E-Health Policy: A Work In Progress. Health Affairs. 2010;29(2): 237-243.

18. Search Storage. Information Life Cycle Management [Internet]. Cited 2010 August 20. Available from: http://searchstorage.techtarget.com/sDefinition/ 0,,sid5_gci963635,00.html

19. Council of European Union. Council conclusions on safe and efficient healthcare through eHealth- 2980 ${ }^{\text {th }}$ Employment, Social Policy, Health and Consumer Afffairs Council Meeting[internet]. 2010 December 01 [cited 2010 August 18]. Available from: http://www.consilium.europa.eu/uedocs/cms_data/docs/pressdata/ en/lsa/111613.pdf

20. Ian Sommerville. Software Engineering, 2009, Eight edition, Chapter2. 47-49 